\title{
Relationship of Eating Patterns and Metabolic Parameters, and Teneligliptin Treatment: Interim Results from Post-marketing Surveillance in Japanese Type 2 Diabetes Patients
}

\author{
Takashi Kadowaki - Masakazu Haneda - Hiroshi Ito · Kazuyo Sasaki (D) • \\ Sonoe Hiraide · Miyuki Matsukawa · Makoto Ueno
}

Received: March 19, 2018 / Published online: May 17, 2018

(C) The Author(s) 2018

\begin{abstract}
Introduction: Healthy eating is a critical aspect of the prevention and management of type 2 diabetes (T2DM). Disrupted eating patterns can result in poor glucose control and increase the likelihood of diabetic complications.
\end{abstract}

Enhanced digital features To view enhanced digital features for this article go to https://doi.org/10.6084/ m9.figshare.6155075.

Electronic supplementary material The online version of this article (https://doi.org/10.1007/s12325018-0704-2) contains supplementary material, which is available to authorized users.

T. Kadowaki

Department of Diabetes and Metabolic Diseases, Graduate School of Medicine, The University of Tokyo, Tokyo, Japan

\section{Haneda}

Department of Medicine, Asahikawa Medical University, Asahikawa, Japan

\section{Haneda}

Medical Corporation Kyousoukai, Osaka, Japan

H. Ito

Department of Cardiovascular Medicine, Okayama University Graduate School of Medicine, Dentistry and Pharmaceutical Sciences, Okayama, Japan

K. Sasaki $(\varangle) \cdot$ S. Hiraide $\cdot$ M. Matsukawa - M. Ueno Ikuyaku Integrated Value Development Division, Mitsubishi Tanabe Pharma Corporation, Osaka, Japan

e-mail: sasaki.kazuyo@mh.mt-pharma.co.jp
Teneligliptin inhibits dipeptidyl peptidase-4 activity for $24 \mathrm{~h}$ and suppresses postprandial hyperglycemia after all three daily meals. This interim analysis of data from the large-scale post-marketing surveillance of teneligliptin (RUBY) in Japan examined eating patterns and their relationship with metabolic parameters and diabetic complications. We also examined whether eating patterns affected safety and efficacy of teneligliptin.

Methods: We analyzed baseline data from survey forms collected in RUBY between May 2013 and June 2017, including patient characteristics, metabolic parameters, and eating patterns (eating three meals per day or not; timing of evening meal) before teneligliptin treatment was initiated. Safety and efficacy of 12 months' teneligliptin (20-40 mg/day) treatment was assessed.

Results: Data from 10,532 patients were available for analysis. Most patients who did not eat three meals per day $(n=757)$ or who ate their evening meal after 10 PM $(n=206)$ were 64 years old or younger. At baseline, glycated hemoglobin (HbA1c), fasting blood glucose, triglycerides, total and low-density lipoprotein cholesterol, body mass index, alanine aminotransferase, and aspartate aminotransferase levels were higher in those patients who did not eat three meals per day $(p<0.05)$ or who ate their evening meal late $(p<0.05)$. Diabetic complications were more common in patients who did not eat three meals per day. Treatment with teneligliptin reduced 
HbA1c over 6 or 12 months across all eating patterns, with a low incidence of adverse drug reactions.

Conclusions: Eating patterns may be associated with altered metabolic parameters and diabetic complications among Japanese patients with T2DM. Teneligliptin may be well tolerated and improve hyperglycemia in patients with T2DM irrespective of eating patterns.

Funding: Mitsubishi Tanabe Pharma Corporation and Daiichi Sankyo Co. Ltd.

Trial Registration Number: Japic CTI-153047.

Keywords: Dipeptidyl peptidase-4 inhibitor; Eating pattern; HbA1c; Post-marketing surveillance; Teneligliptin; Type 2 diabetes

\section{INTRODUCTION}

Chronic hyperglycemia with type 2 diabetes mellitus (T2DM) is associated with an increased risk of microvascular and macrovascular complications, including myocardial infarction, heart failure, or stroke [1]. The prevalence of diabetes, and in particular T2DM, is predicted to increase substantially in coming decades, in line with aging populations [2, 3], increased urbanization [2, 3], reduced physical activity [2], and a change in dietary constituents [2]. A report from the National Health and Nutrition survey in Japan in 2016 estimated that there were 10 million people in whom T2DM was strongly suspected based on reporting a glycated hemoglobin (HbA1c) level of $\geq 6.5 \%$ or being treated for diabetes [4].

Self-care plays an important role in the management of diabetes and its associated complications. In common with various metabolic-related diseases, including obesity [5-7] and non-alcoholic fatty liver disease [8-10], international and national guidance advocates lifestyle management (including healthy eating and physical activity) for the prevention and/or treatment of T2DM [11-13].

Disrupted eating patterns such as fluctuations in the timing of meals (e.g., breakfast skipping, overeating in the evening, or eating the evening meal late) can negatively influence outcomes in patients with diabetes, resulting in poorer glucose control and a greater likelihood of diabetic complications [14-18]. It is known that $\beta$-cell dysfunction greatly contributes to the Japanese T2DM than the Caucasian [19]. There are few reports on large-scale studies on the relationship between eating pattern and glycaemic control in Japanese T2DM patients. In addition, few studies have examined the safety and efficacy of DPP-4 inhibitors due to differences in eating pattern.

Teneligliptin is a novel dipeptidyl peptidase4 (DPP-4) inhibitor that has been prescribed in Japan for the treatment of T2DM since 2012, and in South Korea since 2015. The safety and efficacy of teneligliptin, both as monotherapy and in combination with other antidiabetic agents, has been demonstrated in Japanese patients with T2DM in several clinical studies for up to 52 weeks [20-26]. Teneligliptin was also reported to provide 24 -h DPP-4 inhibition and suppression of postprandial hyperglycemia after each of three meals in a day [20]. RUBY [exploRing the long-term efficacy and safetyincluded cardiovascUlar events in patients with type 2 diaBetes treated bY teneligliptin in the real-world (JapicCTI-153047)] is an ongoing post-marketing surveillance program that aims to verify the long-term safety and efficacy of teneligliptin in $>10,000$ Japanese patients with T2DM [27]. In this surveillance, eating patterns were also recorded to evaluate the impact of teneligliptin on glycemic control in patients according to eating pattern.

The current interim analysis of data from patients registered for the RUBY post-marketing surveillance program examined the relationship between eating patterns and baseline metabolic parameters or diabetic complications. We also examined the safety and efficacy of teneligliptin in patients with T2DM with different eating patterns.

\section{METHODS}

\section{RUBY Design: Patients and Procedure}

Japanese patients with T2DM, who were initiating treatment with teneligliptin for the first time-prescribed at the discretion of the 
treating physician-and who could be observed over the long term, were eligible for participation in the RUBY post-marketing surveillance program [27]. Patients were enrolled between May 2013 and February 2015, and each patient was observed for up to 3 years. Patients were enrolled via a central registration system. An online electronic data capture system was used to gather data from registration and survey forms. This paper reports the results of an interim analysis of survey forms collected between May 2013 and June 2017. The protocol of RUBY surveillance was approved by the Ministry of Health, Labour and Welfare of the Japan Government. The program is ongoing and is carried out by the Mitsubishi Tanabe Pharma Corporation, in accordance with the Japanese Ministry directive on Good Post-marketing Study Practice Guidelines; in compliance with Japanese regulations for post-marketing surveillance, it was not necessary to obtain informed consent from patients. All analyses in the present surveillance were performed on a fully anonymized dataset.

Prescribing physicians recorded the patients' demographics and baseline characteristics, including gender, age, duration of diabetes, medical history, and diabetic and other complications (such as renal disease, hepatic disease, and heart disease), before treatment with teneligliptin was initiated. Moreover, the physicians recorded information regarding the patients' eating patterns and lifestyle interventions at baseline. The questions posed to the patients included: "Do you eat three meals per day?" (answer: yes, no, or unknown; answer "no" if the patient skips meals or frequently snacks between meals) and "What is your normal time for dinner?" (answer: before 6 PM, 6-8 PM, 8-10 PM, after 10 PM, or unknown).

Patients were administered teneligliptin inline with prescribing information, which indicates a usual adult dosage of $20 \mathrm{mg}$ administered orally once daily [28]. If efficacy was considered insufficient, the dose of teneligliptin could be increased up to $40 \mathrm{mg}$ once daily, while closely monitoring the clinical course [28]. Concurrent medications were administered at the discretion of the physician according to relevant treatment guidelines. Physicians completed survey forms at regular intervals following initiation of treatment with teneligliptin for up to 3 years for all enrolled patients. Information including concurrent medications, HbA1c, fasting blood glucose, triglycerides, low-density lipoprotein cholesterol (LDL-cholesterol), high-density lipoprotein cholesterol (HDL-cholesterol), total cholesterol, body mass index (BMI), alanine aminotransferase (ALT), and aspartate aminotransferase (AST) was recorded. The frequency and severity of adverse drug reactions (ADRs; Medical Dictionary for Regulatory Activities/J v.20.0) were recorded. An ADR was defined as an adverse event with a possible causal relationship to teneligliptin, or an unknown relationship. ADRs considered to be of special interest included: hypoglycemia-related ADR (severe hypoglycemia was defined as blood glucose $\leq 50 \mathrm{mg} / \mathrm{dL}$ or as judged by the physician), skin and subcutaneous tissue disorders, gastrointestinal disorders (including pancreatitis and intestinal obstruction), hepatic impairment, and renal impairment.

\section{Interim Analysis}

An interim analysis of survey forms collected between May 2013 and June 2017 examined the relationship between eating patterns (whether the patient ate three meals per day and timing of evening meal) and baseline metabolic parameters or the prevalence of diabetic complications (diabetic retinopathy, nephropathy, and neuropathy). The impact of eating patterns on the incidence of ADRs and changes in HbA1c following administration of teneligliptin for 12 months was also studied. Analyses for the relationship between eating patterns and safety of teneligliptin were performed on the safety analysis set (all enrolled patients who had at least one safety assessment after receiving at least one dose of teneligliptin), and analysis for the efficacy of teneligliptin was performed on the efficacy analysis set (all enrolled patients who had at least one efficacy assessment after receiving at least one dose of teneligliptin) [27]. 


\section{Statistical Analysis}

Statistical analyses were performed using SAS v.9.1.3 (SAS Institute, Cary, NC, USA). Continuous data were summarized using descriptive statistics. Discrete data were summarized based on the number and percentage values for each category. The relationship between eating pattern (three meals per day and timing of evening meal) and metabolic parameters was analyzed using a two-sample $t$ test for "three meals per day" and one-way analysis of variance (ANOVA) using contrast $(-1,-1 / 3,1 / 3,1)$ of each category for "timing of evening meal", respectively. Analysis of covariance was also performed to adjust for patient gender and age. The relationship between eating pattern and diabetic complications (diabetic retinopathy, nephropathy, and neuropathy) was analyzed using Chi square tests. Given that data regarding eating patterns were only recorded prior to initiation of teneligliptin, and acknowledging that eating patterns may have changed during 3 years of surveillance, assessments of teneligliptin treatment were made up to the first 12 months only in the current analysis. A onesample $t$ test was performed between HbA1c levels at baseline and after 6 months or 12 months of teneligliptin treatment for each eating pattern. A significance level of 5\% and two-sided $95 \%$ confidence intervals were defined.

\section{RESULTS}

\section{Patient Demographics and Baseline Characteristics}

From a total of 11,677 Japanese patients with diabetes enrolled in the RUBY surveillance program, the survey forms for 10,532 patients in the safety analysis set were available for this interim analysis. Patient demographics and baseline characteristics are presented in Table 1. The mean age [standard deviation (SD)] of patients included in the analysis was 65.4 (12.4) years and $60.2 \%$ of the population was male. Mean (SD) baseline HbA1c was 7.8 (1.5)\% and baseline BMI was $25.3(4.4) \mathrm{kg} / \mathrm{m}^{2}$. The mean
Table 1 Patient demographics and baseline characteristics

\begin{tabular}{llc}
\hline All patients & $(n=10,532)$ & \\
\hline Male sex, $n$ (\%) & & $6338(60.2)$ \\
Age (years) & $(n=10,532)$ & $65.4(12.4)$ \\
Body weight $(\mathrm{kg})$ & $(n=7661)$ & $65.50(14.34)$ \\
BMI $\left(\mathrm{kg} / \mathrm{m}^{2}\right)$ & $(n=7009)$ & $25.26(4.40)$ \\
HbAlc $(\%)$ & $(n=9663)$ & $7.76(1.52)$ \\
Fasting blood glucose & $(n=3659)$ & $151.9(52.5)$ \\
$\quad$ (mg/dL) & & \\
Fasting insulin ( $\mu \mathrm{U} / \mathrm{mL})$ & $(n=590)$ & $9.90(9.77)$ \\
ALT (IU/L) & $(n=7942)$ & $28.8(23.4)$ \\
AST (IU/L) & $(n=7902)$ & $26.6(16.8)$ \\
Duration of T2DM & $(n=7230)$ & $7.38(7.86)$ \\
$\quad$ (years) & & \\
Diabetic complications, \\
$n$ (\%)
\end{tabular}


Table 1 continued

\begin{tabular}{lc}
\hline All patients & $(\boldsymbol{n}=\mathbf{1 0 , 5 3 2})$ \\
\hline Sulfonylurea & $2320(22.0)$ \\
Thiazolidine & $774(7.3)$ \\
Biguanide & $1719(16.3)$ \\
$\alpha$-Glucosidase inhibitor & $1056(10.0)$ \\
Glinide & $373(3.5)$ \\
Insulin & $710(6.7)$ \\
SGLT2 inhibitor & $27(0.3)$ \\
Antidyslipidemic agents & $3704(35.2)$ \\
at initiation & \\
of teneligliptin, $n(\%)$ & \\
\hline
\end{tabular}

Data are mean (SD) unless otherwise stated

$A L T$ alanine aminotransferase, $A S T$ aspartate aminotransferase, $B M I$ body mass index, $H b A 1 c$ glycated hemoglobin, $n$ number of patients, $S D$ standard deviation, SGLT2 sodium-glucose co-transporter-2, T2DM type 2 diabetes mellitus

duration of diabetes was 7.4 (7.9) years and approximately one-quarter of patients $(26.1 \%)$ reported some form of diabetic complication, of which diabetic nephropathy was the most common (18.7\%). Of other complications reported, hypertension and dyslipidemia occurred in $62.6 \%$ and $65.6 \%$ of patients, respectively. The proportions of patients on dietary therapy and exercise therapy were $76.1 \%$ and $58.9 \%$, respectively.

At baseline, teneligliptin was initiated as monotherapy in $52.5 \%$ of patients, while $47.5 \%$ patients started teneligliptin therapy in combination with other diabetes drugs. The most commonly prescribed antidiabetic drugs were sulfonylurea $(22.0 \%)$ or biguanide $(16.3 \%)$ (Table 1). At baseline, $35.2 \%$ of patients were taking antidyslipidemic agents.

\section{Eating Patterns}

Of the 10,532 patients, $77.3 \%$ consumed three meals per day and $7.2 \%$ did not consume three meals per day (Fig. 1a). Of the overall patient population, $43.0 \%$ were $\leq 64$ years of age, $31.5 \%$ were $65-74$ years of age, and $25.5 \%$ were $\geq 75$ years of age. Of the 8136 patients consuming three meals per day, $40.2 \%$ were $\leq 64$ years of age, $32.4 \%$ were $65-74$ years of age, and $27.4 \%$ were $\geq 75$ years of age (Fig. 1b). Patients $\leq 64$ years of age accounted for $62.4 \%$ of patients who did not eat three meals per day.

The most common time for eating the evening meal was between 6 and 8 PM (Fig. 1c). Patients $\leq 64$ years of age accounted for $72.1 \%$ and $81.1 \%$ of patients who ate their evening meal at 8-10 PM and after 10 PM, respectively, compared with $12.6 \%$ and $36.1 \%$ of those eating before $6 \mathrm{PM}$ and between 6 and $8 \mathrm{PM}$, respectively (Fig. 1d).

\section{Eating Patterns and Metabolic Parameters at Baseline}

Figure 2 and Fig. S1 show the relationship between eating patterns and various metabolic parameters at baseline. HbA1c levels were higher in those patients who did not eat three meals per day $(p<0.001)$; mean (SD) HbA1c was 8.41 (1.86)\% compared with 7.68 (1.47)\% in those patients who ate three meals per day. Mean (SD) fasting blood glucose, triglycerides, LDL-cholesterol, total cholesterol, and BMI were also significantly higher in patients who did not eat three meals per day than those who ate three meals per day [172.4 (69.7) vs. 148.6 (49.4) $\mathrm{mg} / \mathrm{dL}, \quad 186.8 \quad(159.6) \quad$ vs. 162.2 (124.4) mg/dL, 121.0 (35.8) vs. 113.8 (32.3) mg/ $\mathrm{dL}, 202.2$ (45.0) vs. $194.2(40.0) \mathrm{mg} / \mathrm{dL}$, and $26.38(5.38)$ vs. $25.13(4.25) \mathrm{kg} / \mathrm{m}^{2}$, respectively; all $p<0.001]$. Moreover, mean (SD) ALT and AST levels were significantly higher in patients who did not eat three meals per day compared with those who ate three meals per day [33.8 (29.0) vs. $28.1(21.9) \mathrm{IU} / \mathrm{L} ; p<0.001$, and 28.2 (18.3) vs. $26.3 \quad(16.0) \mathrm{IU} / \mathrm{L} ; \quad p=0.019$, respectively].

Additionally, HbA1c, fasting blood glucose, triglycerides, LDL-cholesterol, total cholesterol, BMI, ALT, and AST all increased with lateness of eating dinner (all $p<0.05$; Fig. 2 and Fig. S1). 
(a)
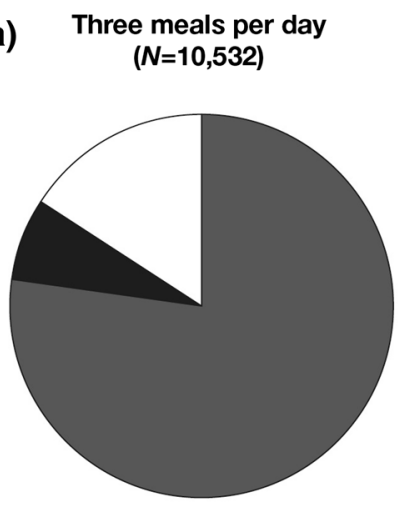

$\operatorname{Yes}_{(n=8,136)}^{\text {No }} \square$ Unknown

(c)

Evening meal time $(N=10,532)$

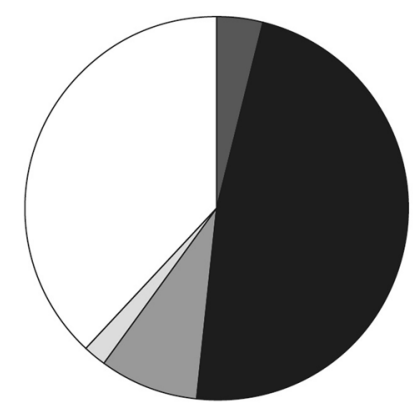

(b)

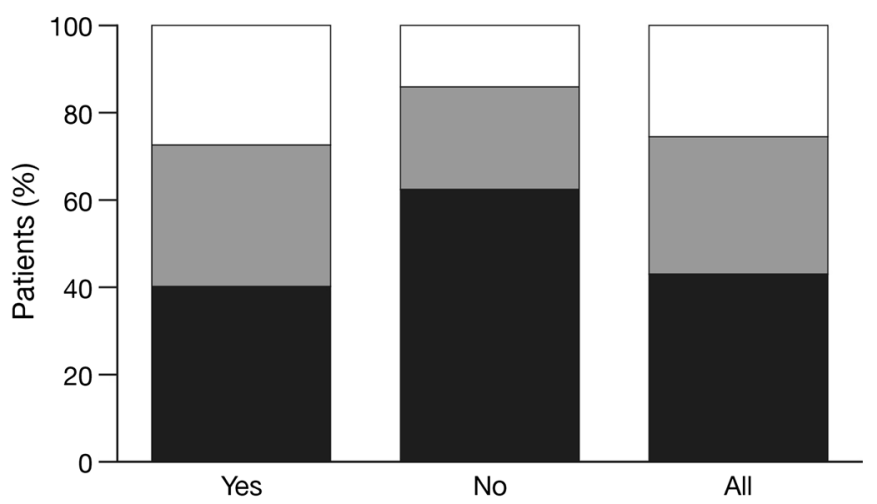

$\leqslant 64$ years $(n=4,527)$

65-74 years $(n=3,320)$

$\square \geqslant 75$ years $(n=2,685)$ (d)

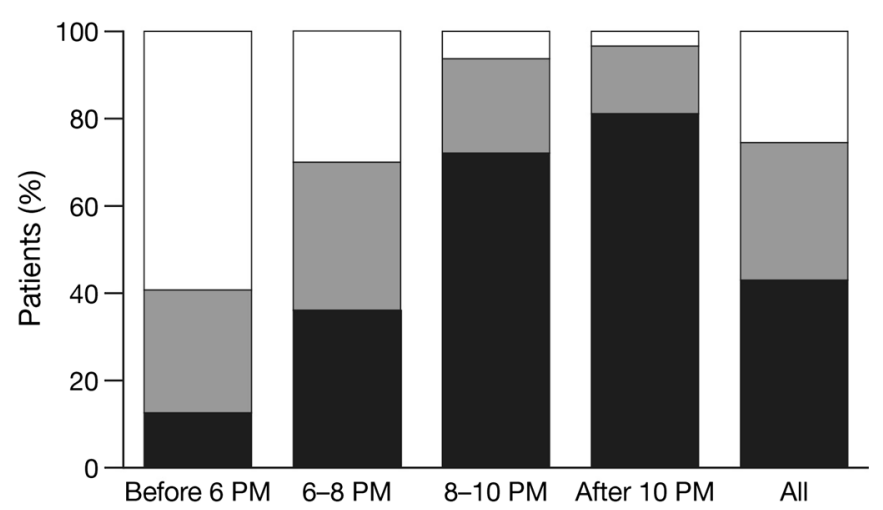

Before 6 PM $(n=413)$

$\square$ After 10 PM $(n=206)$

Fig. 1 Eating patterns: a proportion of patients eating three meals per day or not (a "no" response means not eating three meals per day); $\mathbf{b}$ proportion of patients in each age group eating three meals per day or not;

Patients who ate dinner before $6 \mathrm{PM}$ and those who ate dinner after $10 \mathrm{PM}$ had a mean (SD) HbA1c of $7.33 \quad(1.23) \%$ and 8.19 (1.59)\%, respectively. For patients who ate dinner $6 \mathrm{PM}$ or after 10 PM, mean (SD) values, respectively, were as follows: fasting blood glucose, 139.6 (45.5) and 159.7 (56.7) $\mathrm{mg} / \mathrm{dL}$; triglycerides, 141.4 (84.0) and 178.7 (140.1) mg/dL; LDL-c- c proportion of patients by timing of evening meal; and d proportion of patients in each age group by timing of evening meal

holesterol, 109.3 (34.0) and 119.1 (33.8) $\mathrm{mg} / \mathrm{dL}$; total cholesterol, $185.8 \quad(38.5)$ and 201.1 (41.2) $\mathrm{mg} / \mathrm{dL}$; and BMI, 24.22 (4.03) and 26.83 (4.92) $\mathrm{kg} / \mathrm{m}^{2}$. Mean (SD) ALT and AST levels in patients who ate dinner before after $6 \mathrm{PM}$ and in those who ate dinner after after 10 PM were 21.7 (15.9) and 36.7 (26.7) IU/L, and 24.6 (14.8) and 27.8 (15.4) IU/L, respectively. No discernible 
relationship was observed between eating patterns and HDL-cholesterol (Fig. S1).

Analysis of eating patterns adjusted for the sex and age of the patient showed a tendency towards higher HbA1c, fasting glucose, triglycerides, LDL-cholesterol, total cholesterol, BMI, and ALT levels in patients not eating three meals per day compared with those eating three meals per day (Table S1). In the sex- and ageadjusted analyses for evening meal time, HbA1c, fasting glucose, triglycerides, BMI, and ALT levels increased or tended to increase with lateness of eating dinner, although statistical power was limited due to the smaller sample size of patients $\geq 65$ years of age who ate dinner late (Table S1).

\section{Eating Patterns and Diabetic Complications at Baseline}

Diabetic neuropathy and retinopathy were more prevalent in patients who did not eat three meals per day $(13.1 \%$ and $12.9 \%$, respectively) compared with those eating three meals per day $(9.9 \%$ and $9.3 \%$, respectively; $p=0.007$ and $p=0.002$ for neuropathy and retinopathy, respectively; Fig. 3). No significant difference in the prevalence of nephropathy was observed. There was no clear relationship between the prevalence of diabetic complications and the time at which the evening meal was consumed.

\section{Eating Patterns and Safety of Teneligliptin}

The incidence of ADRs following 12 months of treatment with teneligliptin is shown in Table 2. The overall incidence of ADRs in each eating pattern (three meals per day and timing of evening meal) was $1.94-3.43 \%$. Eating patterns had no discernible influence on the incidence and nature of ADRs following the administration of teneligliptin. Although the incidence of ADRs related to hepatic impairment was higher in the patients not eating three meals per day than in patients eating three meals per day [0.79 (6 patients) vs. 0.23\% (19 patients)], the relationship to teneligliptin in three of these six patients was unknown.

\section{Eating Patterns and Efficacy of Teneligliptin}

HbA1c-lowering effects of teneligliptin over a period of 6 or 12 months of treatment was observed for each eating pattern. Among patients who consumed three meals per day, mean (SD) HbA1c showed a significant reduction from baseline [7.68 (1.46)\%] to 6 months [6.94 (1.01)\%; $p<0.001]$ and 12 months [6.95 (1.00)\%; $p<0.001]$ (Fig. 4). For patients who did not eat three meals per day, HbA1c decreased significantly from baseline [8.38 $(1.84) \%]$ at both 6 months [7.27 (1.31)\%; $p<0.001]$ and 12 months [7.25 (1.22)\%; $p<0.001]$. Of patients with baseline HbA1c $\geq 7.0 \%, 47.0 \%$ of patients who ate three meals per day and $40.6 \%$ of those who did not eat three meals per day achieved HbA1c $<7.0 \%$ after 12 months of treatment with teneligliptin.

Similarly, the HbA1c-lowering effects of treatment with teneligliptin were observed at 6 and 12 months in each timing of the evening meal ( $p<0.001$ for all; Fig. 4$)$. The mean (SD) HbA1c levels at baseline, and after 6 and 12 months of treatment in patients eating before 6 PM were $7.32(1.23) \%, 6.79(0.90) \%$, and $6.70(0.90) \%$, respectively. In patients eating after $10 \mathrm{PM}$, the mean $\mathrm{HbA} 1 \mathrm{c}$ levels were $8.20(1.60) \%, 7.34(1.37) \%$, and 7.58 (1.57)\%, respectively. Of patients with baseline HbA1c $\geq 7.0 \%$, the percentage who achieved HbA1c $<$ $7 \%$ after 12 months of treatment with teneligliptin declined with the lateness of eating their evening meal $(54.4,47.9,42.9$, and $33.0 \%$ of those who ate their evening meal before 6 PM, 6-8 PM, 8-10 PM, after 10 PM, respectively).

\section{DISCUSSION}

This large-scale analysis of eating patterns in a real-world sample shows that the number of meals consumed and the timing of the evening meal may be associated with differences not only in glycemic control but also in blood lipids, obesity, and liver function in Japanese patients with T2DM. Moreover, the number of meals consumed may be associated with 

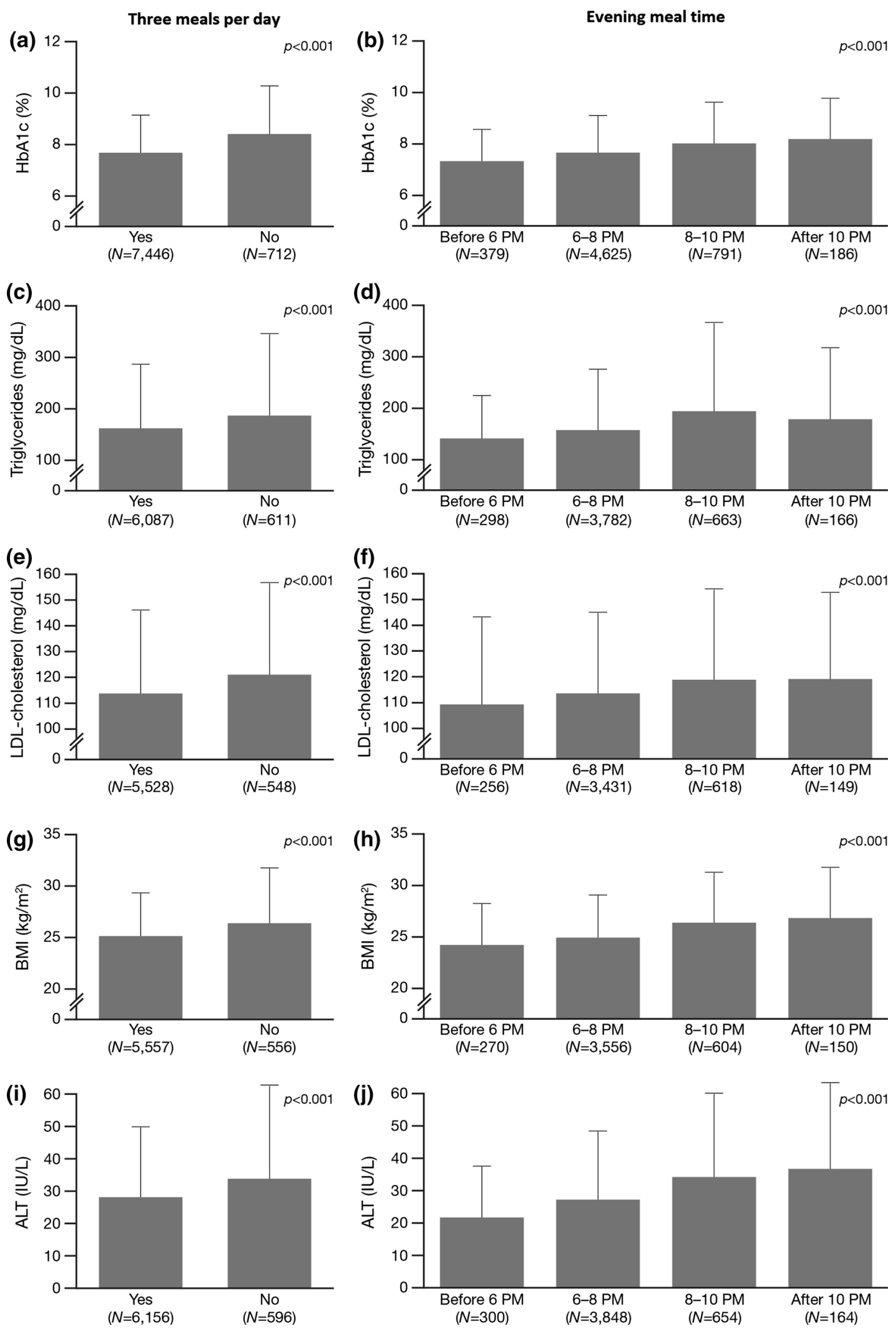
4Fig. 2 Relationship between eating patterns and baseline: a, b HbAlc; c, d triglycerides; e, f LDL-cholesterol; g, h BMI; and i, j ALT. Data are presented as mean and standard deviation. The relationship between eating pattern and metabolic parameters was analyzed using two-sample $t$-test (three meals per day) and one-way ANOVA (evening meal time). ALT alanine aminotransferase; $A N O V A$ analysis of variance; $B M I$ body mass index; $H b A 1 c$ glycated hemoglobin; $L D L$ low-density lipoprotein

diabetic complications. HbA1c-lowering effects with a low incidence of ADRs were observed with the DPP-4 inhibitor, teneligliptin, over a period of 6 or 12 months in patients both with, and without, appropriate eating patterns.

International and national guidance advocates lifestyle management (including healthy eating and physical activity) for the prevention and/or management of T2DM [11-13]. Such guidance is vindicated by data from the Look AHEAD study, which examined the long-term effects of intensive lifestyle intervention in > 5000 patients with T2DM, and observed improved glycemic control, lower risk of cardiovascular disease, and reduced healthcare utilization among patients adopting the strategy [29-31].

In the current analysis, most of the sample population consumed three meals per day, and ate their evening meal between 6 and $8 \mathrm{PM}$. However, people $\leq 64$ years of age were most likely not to manage a three-meals-per-day eating schedule and were more likely to consume their evening meal later in the evening. One of the reasons for irregular eating patterns among non-elderly patients in the current analysis may be their lifestyle characteristics, such as nocturnal living, longer working hours, or singleperson households.

Among people with and without T2DM, breakfast skipping and/or snacking can lead to poor glucose control [14-17, 32, 33]. Skipping breakfast has been associated with significantly more pronounced hyperglycemic response and impaired insulin response after subsequent lunch and dinner [16]. It has been reported that night-eating behaviors may predispose patients to diabetic complications [15]. Moreover, late evening meals have been shown to increase the risk of developing T2DM [18, 34]. For example, eating dinner within $2 \mathrm{~h}$ before bedtime has been linked to the development of hyperglycemia in a cross-sectional sample of $>61,000$ apparently healthy Japanese adults [34]. Our findings support these observations that eating patterns may be associated with alterations in metabolic parameters and diabetic complications among Japanese patients with T2DM. Many patients with diabetes have complications such as dyslipidemia, obesity, or non-alcoholic fatty liver disease $[9,35-37]$. In common with diabetes, dietary intervention is heavily recommended in the management of these disorders [5-10, 38, 39]. Unhealthy eating pattern in young people caused by characteristic lifestyles may be associated with future much advanced metabolic disorders. Our results may be helpful in the clinical management of metabolic disorders other than diabetes.

The timing of meals is believed to link to circadian rhythms in metabolic organs. The circadian clock has been reported to regulate metabolism and energy homeostasis in the peripheral tissues [40, 41]. This includes many of the metabolic pathways, such as insulin secretion from $\beta$-cells, insulin sensitivity, glucose metabolism, and lipid metabolism [40, 41]. For example, the heterodimeric transcription factor complex of circadian locomotor output cycles kaput (CLOCK) and brain and muscle aryl hydrocarbon receptor nuclear translocatorlike protein (BMAL)-1 have demonstrated their role in controlling insulin secretion from pancreatic $\beta$-cells and in regulating muscle insulin sensitivity through sirtuin 1 [42, 43]. Therefore, the management of eating patterns is important to prevent the development and progression of diabetes and its associated complications.

Teneligliptin has been reported to inhibit DPP-4 activity for $24 \mathrm{~h}$ and suppression of postprandial hyperglycemia after all three daily meals [20]. Treatment with teneligliptin for up to 12 months was well tolerated and reduced HbA1c levels in each eating pattern in the current analysis. However, after 6 and 12 months of treatment, mean HbA1c levels of $<7.0 \%$ were only achieved in patients eating three meals per day and not in those without this eating pattern. Such a distinction was also 
(a)

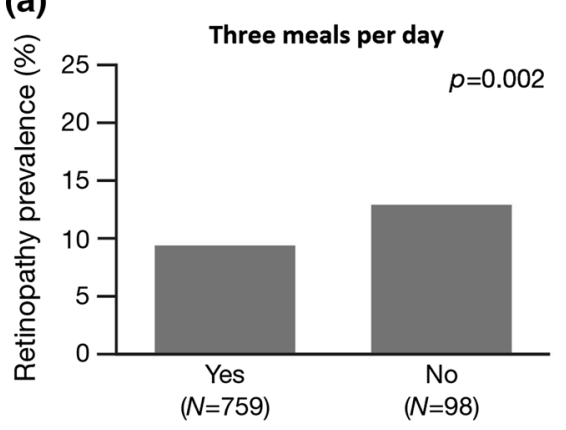

(c)

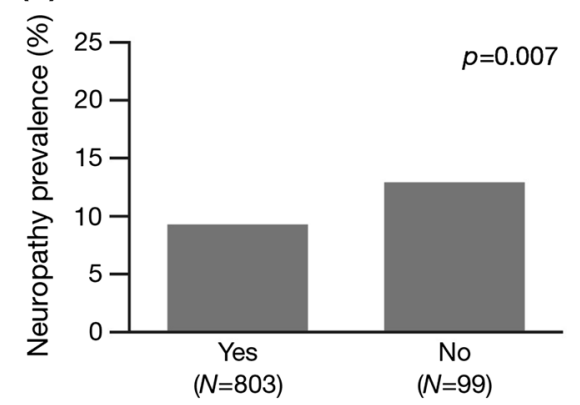

(e)

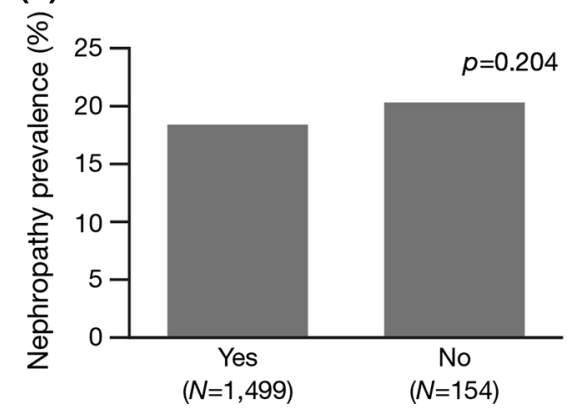

(b)

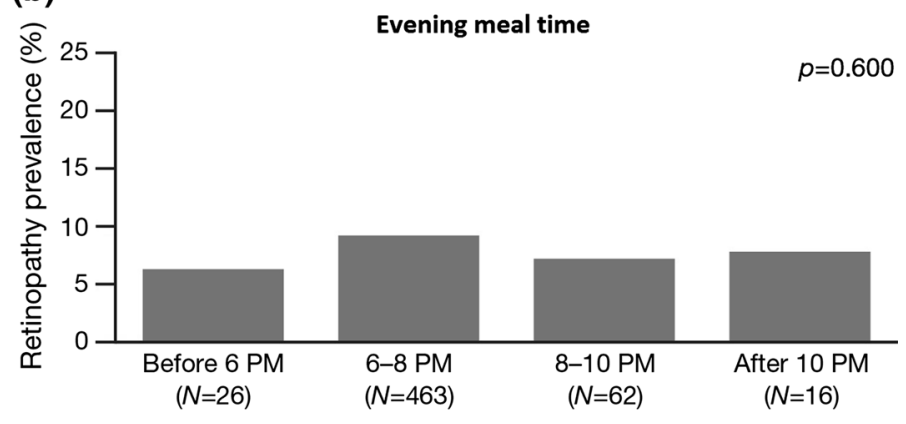

(d)

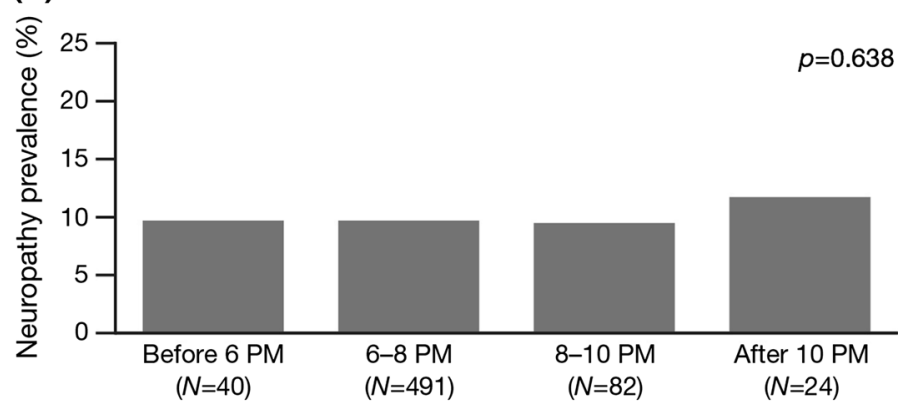

(f)

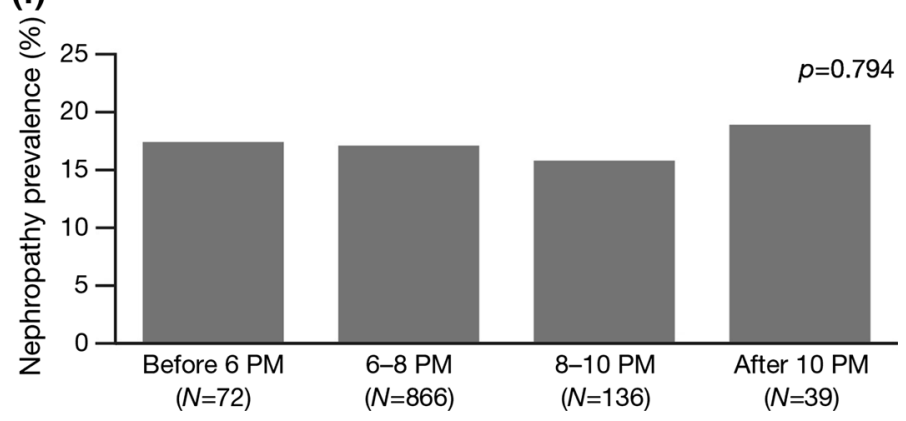

Fig. 3 Relationship between eating patterns and prevalence of: a, b retinopathy; c, d neuropathy; and e, f nephropathy. The relationship between eating pattern

observed between patients eating their evening meal early (before $8 \mathrm{PM}$ ) and late (after $8 \mathrm{PM}$ ) following active treatment, with early eaters achieving a reduction of mean HbA1c levels to $<7.0 \%$. These results suggest that in order to achieve HbA1c $<7.0 \%$, it is important to manage dietary patterns, in addition to optimizing pharmacotherapeutic management. These finding may be helpful in information in pharmacotherapy with appropriate dietary therapy for patients with T2DM.

This analysis has several notable limitations. Questions regarding eating patterns (i.e., and diabetic complications was analyzed using Chi square test. $n$ values indicate the number of patients with the complication

whether the patient eats three meals per day) were structured to allow for only "yes" or "no" responses, and so we are unable to further delineate whether a "no" answer to this question meant fewer or more than three meals per day. More detailed questioning regarding the frequency of skipping meals or between-meal snacking, and the size/quality/composition of meals and snacking would also have been informative. Although there was no clear relationship between eating three meals per day or not and the incidence of hypoglycaemia in this surveillance, consuming supplemental 
Table 2 Incidence of adverse drug reactions (up to 12 months of treatment with teneligliptin; safety population)

\begin{tabular}{|c|c|c|c|c|c|c|}
\hline & \multicolumn{2}{|c|}{ Three meals per day } & \multicolumn{4}{|c|}{ Evening meal time } \\
\hline & $\begin{array}{l}\text { Yes } \\
(n=8136)\end{array}$ & $\begin{array}{l}\text { No } \\
(n=757)\end{array}$ & $\begin{array}{l}\text { Before 6 PM } \\
(n=413)\end{array}$ & $\begin{array}{l}\text { 6-8 PM } \\
(n=5059)\end{array}$ & $\begin{array}{l}\text { 8-10 PM } \\
(n=861)\end{array}$ & $\begin{array}{l}\text { After 10 PM } \\
(n=206)\end{array}$ \\
\hline Any ADR & $195(2.40)$ & $26(3.43)$ & $11(2.66)$ & $111(2.19)$ & $24(2.79)$ & $4(1.94)$ \\
\hline Serious ADR & $33(0.41)$ & $5(0.66)$ & $1(0.24)$ & $16(0.32)$ & $2(0.23)$ & $1(0.49)$ \\
\hline \multicolumn{7}{|c|}{ Breakdown of main ADR } \\
\hline Hypoglycemia & $21(0.26)$ & $2(0.26)$ & $0(0.00)$ & $10(0.20)$ & $3(0.35)$ & $1(0.49)$ \\
\hline SST disorders & $23(0.28)$ & $3(0.40)$ & $1(0.24)$ & $12(0.24)$ & $5(0.58)$ & $0(0.00)$ \\
\hline GI disorders & $40(0.49)$ & $5(0.66)$ & $5(1.21)$ & $20(0.40)$ & $5(0.58)$ & $1(0.49)$ \\
\hline $\begin{array}{l}\text { Hepatic } \\
\text { impairment }\end{array}$ & $19(0.23)$ & $6(0.79)$ & $2(0.48)$ & $10(0.20)$ & $3(0.35)$ & $2(0.97)$ \\
\hline $\begin{array}{l}\text { Renal } \\
\text { impairment }\end{array}$ & $13(0.16)$ & $2(0.26)$ & $0(0.00)$ & $8(0.16)$ & $4(0.46)$ & $0(0.00)$ \\
\hline
\end{tabular}

Data are number of patients (\%)

$A D R$ adverse drug reaction, GI gastrointestinal, $S S T$ skin and subcutaneous tissue

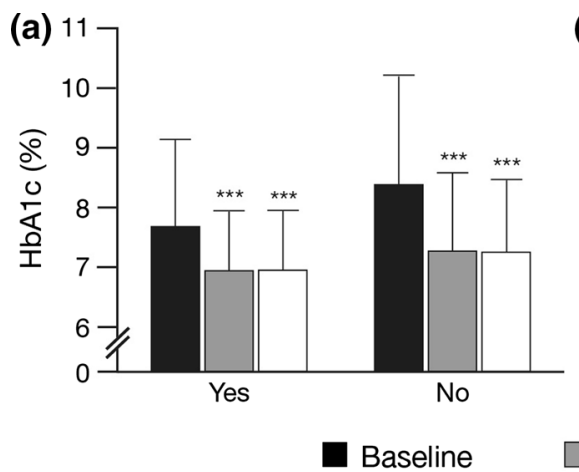

Fig. 4 Glycemic control after administration of teneligliptin for 6 and 12 months in patients: a with three meals per day or not; and $\mathbf{b}$ by evening meal time. Data are presented

carbohydrates were reported to prevent hypoglycaemia [13]. Additionally, adherence to medical treatment, physical activity, and other lifestyle factors were not assessed. Eating patterns were recorded only at the beginning of the observation and, consequently, do not take into account any changes in eating patterns that occurred while treatment was ongoing. The analysis did not take into account any changes in concurrent antidiabetic treatments or lifestyle modifications over the course of treatment with teneligliptin. There are some of the typical limitations of a post-marketing surveillance design, which include having incomplete data, possible reporting biases, no matched control group, and limitations in the generalizability of the findings. These limitations should be taken into account when interpreting these data. 


\section{CONCLUSIONS}

In conclusion, this interim analysis shows that the eating patterns of Japanese adults with T2DM vary according to age, with poor management of eating behaviors in non-elderly patients. We also demonstrate that eating patterns may be related not only to glycemic control-which, in turn, may eventually be related to the risk of developing diabetic complications-but also to blood lipid levels, obesity, and liver function. These findings support the importance of eating patterns on the management of diabetes and its associated complications. Teneligliptin may be well tolerated and improve hyperglycemia in patients with T2DM with and without appropriate eating patterns. Treatment with teneligliptin in addition to management of dietary patterns may further improve glycemic control.

\section{ACKNOWLEDGEMENTS}

We would like to extend our sincerest gratitude to all participants and physicians and physicians at the participating facilities. We would also like to acknowledge the contributions of Mr. K. Yoshida for survey forms collection, Ms. R. Wakamoto for data management, and Ms. T. Yamakura for insightful discussions.

Funding. The RUBY surveillance program was funded by Mitsubishi Tanabe Pharma Corporation, and Daiichi Sankyo Co. Ltd. Medical writing support was funded by the Mitsubishi Tanabe Pharma Corporation, Osaka, Japan. The article processing charges and open access fee for this publication were funded by Mitsubishi Tanabe Pharma Corp. All authors had full access to all of the data in this study and take complete responsibility for the integrity of the data and accuracy of the data analysis.

Authorship. All named authors meet the International Committee of Medical Journal Editors (ICMJE) criteria for authorship for this article, take responsibility for the integrity of the work as a whole, and have given their approval for this version to be published.

Author Contributions. Takashi Kadowaki, Masakazu Haneda, and Hiroshi Ito, all contributed to the data interpretation and provided medical advice. Kazuyo Sasaki, Makoto Ueno, and Sonoe Hiraide contributed to the conception of the surveillance and data interpretation. Miyuki Matsukawa contributed to the analyses and data interpretation. All authors contributed to the manuscript development.

Medical Writing, Editorial, and Other Assistance. Medical writing support, under the direction of the authors, was provided by Caroline Shepherd, B.Pharm. of CMC CONNECT, a division of Complete Medical Communications Ltd, Macclesfield, UK, and Janet Dawson PhD, on behalf of CMC CONNECT, funded by Mitsubishi Tanabe Pharma Corporation, in accordance with Good Publication Practice (GPP3) guidelines.

Disclosures. Takashi Kadowaki has received speaker honorarium/lecture fees from Astellas Pharma Inc., AstraZeneca K.K., Eli Lilly Japan K.K., Kowa Pharmaceutical Co., Ltd., Mitsubishi Tanabe Pharma Corporation, MSD K.K., Nippon Boehringer Ingelheim Co., Ltd., Novo Nordisk Pharma Ltd., Ono Pharmaceutical Co., Ltd., and Takeda Pharmaceutical Co., Ltd.; has received research grants from Daiichi Sankyo Co., Ltd., Novartis Pharma K.K., and Takeda Pharmaceutical Co., Ltd.; has received scholarship grants from Astellas Pharma Inc., Daiichi Sankyo Co., Ltd., Kissei Pharmaceutical Co., Ltd., Kyowa Hakko Kirin Co., Ltd., Mitsubishi Tanabe Pharma Corporation, Novo Nordisk Pharma Ltd., Ono Pharmaceutical Co., Ltd., Sanofi K. K., Sumitomo Dainippon Pharma Co., Ltd., Taisho Toyama Pharmaceutical Co., Ltd., and Takeda Pharmaceutical Co., Ltd.; and has belonged to courses endowed by Kowa Pharmaceutical Co., Ltd., Mitsubishi Tanabe Pharma Corporation, MSD K.K., Nippon Boehringer Ingelheim Co., Ltd., Novo Nordisk Pharma Ltd., Ono Pharmaceutical Co., Ltd., and Takeda Pharmaceutical Co., Ltd.

Masakazu Haneda has received speaker honorarium/lecture fees from Astellas Pharma Inc., 
Kowa Pharmaceutical Co., Ltd., Mitsubishi Tanabe Pharma Corporation, MSD K.K., Nippon Boehringer Ingelheim Co., Ltd., Novartis Pharma K.K., Novo Nordisk Pharma Ltd., Ono Pharmaceutical Co., Ltd., Sanofi K.K., Taisho Pharmaceutical Co., Ltd., and Taisho Toyama Pharmaceutical Co., Ltd.; and has received scholarship grants from Astellas Pharma Inc., Daiichi Sankyo Co., Ltd., Eli Lilly Japan K.K., Johnson \& Johnson K.K., Kissei Pharmaceutical Co., Ltd., Kowa Pharmaceutical Co., Ltd., Kyowa Hakko Kirin Co., Ltd., Mitsubishi Tanabe Pharma Corporation, MSD K.K., Nippon Boehringer Ingelheim Co., Ltd., Novo Nordisk Pharma Ltd., Ono Pharmaceutical Co., Ltd., Otsuka Pharmaceutical Co., Ltd., Sanofi K.K., Shionogi \& Co., Ltd., Taisho Toyama Pharmaceutical Co., Ltd., and Takeda Pharmaceutical Co., Ltd.

Hiroshi Ito has received speaker honorarium/ lecture fees from Daiichi Sankyo Co., Ltd. and Mitsubishi Tanabe Pharma Corporation, and has received scholarship grants from Daiichi Sankyo Co., Ltd. and Mitsubishi Tanabe Pharma Corporation. Kazuyo Sasaki is an employee of the Mitsubishi Tanabe Pharma Corporation. Makoto Ueno is an employee of the Mitsubishi Tanabe Pharma Corporation. Sonoe Hiraide is an employee of the Mitsubishi Tanabe Pharma Corporation. Miyuki Matsukawa is an employee of the Mitsubishi Tanabe Pharma Corporation.

Compliance with Ethics Guidelines. The protocol of RUBY surveillance was approved by the Ministry of Health, Labour and Welfare of the Japan Government. The post-marketing surveillance program is ongoing and is carried out by the Mitsubishi Tanabe Pharma Corporation, in accordance with the Japanese Ministry directive on Good Post-marketing Study Practice Guidelines; in compliance with Japanese regulations for post-marketing surveillance, it was not necessary to obtain informed consent from patients. All analyses in the present surveillance were performed on a fully anonymized dataset.

Data Availability. The datasets analyzed during the current study are not publicly available due to protection of individual patient confidentiality, but are available from the corresponding author on reasonable request.

Open Access. This article is distributed under the terms of the Creative Commons Attribution-NonCommercial 4.0 International License (http://creativecommons.org/licenses/ by-nc/4.0/), which permits any noncommercial use, distribution, and reproduction in any medium, provided you give appropriate credit to the original author(s) and the source, provide a link to the Creative Commons license, and indicate if changes were made.

\section{REFERENCES}

1. Stratton IM, Adler AI, Neil HAW, et al. Association of glycaemia with macrovascular and microvascular complications of type 2 diabetes (UKPDS 35): prospective observational study. BMJ. 2000;321:405-12.

2. World Health Organization, Food and Agriculture Organization. Diet, nutrition and the prevention of chronic diseases. Report of a joint WHO/FAO expert consultation. http://apps.who.int/iris/bitstream/ 10665/42665/1/WHO_TRS_916.pdf. Accessed 12 Jan 2018.

3. Guaríguata L, Whiting DR, Hambleton I, Beagley J, Linnenkamp U, Shaw JE. Global estimates of diabetes prevalence for 2013 and projections for 2035 . Diabetes Res Clin Pract. 2014;103:137-49.

4. National Health and Nutrition Survey in Japan 2016. http://www.mhlw.go.jp/file/04-Houdouhapp you-10904750-Kenkoukyoku-Gantaisakukenkou zoushinka/kekkagaiyou_7.pdf. Accessed 12 Jan 2018.

5. Jensen MD, Ryan DH, Apovian CM, et al. 2013 AHA/ACC/TOS guideline for the management of overweight and obesity in adults: a report of the American College of Cardiology/American Heart Association Task Force on Practice Guidelines and The Obesity Society. Circulation. 2014;129(25 Suppl 2):S102-38.

6. Yumuk V, Tsigos C, Fried M, et al. European guidelines for obesity management in adults. Obes Facts. 2015;8:402-24.

7. Garvey WT, Mechanick JI, Brett EM, et al. American Association of Clinical Endocrinologists and American College of Endocrinology Comprehensive Clinical Practice Guidelines for Medical Care of 
Patients with Obesity. Endocr Pract. 2016;22(Suppl 3):1-203.

8. Chalasani N, Younossi Z, Lavine JE, et al. The diagnosis and management of non-alcoholic fatty liver disease: practice guideline by the American Gastroenterological Association, American Association for the Study of Liver Diseases, and American College of Gastroenterology. Gastroenterology. 2012;142:1592-609.

9. European Association for the Study of the Liver (EASL), European Association for the Study of Diabetes (EASD), European Association for the Study of Obesity (EASO). EASL-EASD-EASO Clinical Practice Guidelines for the management of non-alcoholic fatty liver disease. Diabetologia. 2016;59:1121-40.

10. Watanabe S, Hashimoto E, Ikejima K, et al. Evidence-based clinical practice guidelines for nonalcoholic fatty liver disease/nonalcoholic steatohepatitis. J Gastroenterol. 2015;50:364-77.

11. Inzucchi SE, Bergenstal RM, Buse JB, et al. Management of hyperglycaemia in type 2 diabetes: a patient-centered approach. Position statement of the American Diabetes Association (ADA) and the European Association for the Study of Diabetes (EASD). Diabetologia. 2012;55:1577-96.

12. Araki E, Haneda M, Kasuga M, et al. New glycemic targets for patients with diabetes from the Japan Diabetes Society. J Diabetes Investig. 2017;8:123-5.

13. American Diabetes Association. Standards of medical care in diabetes-2018. 4. Lifestyle management. Diabetes Care. 2018;41(Suppl 1):S38-50.

14. Bi H, Gan Y, Yang C, Chen Y, Tong X, Lu Z. Breakfast skipping and the risk of type 2 diabetes: a meta-analysis of observational studies. Public Health Nutr. 2015;18:3013-9.

15. Morse SA, Ciechanowski PS, Katon WJ, Hirsch IB. Isn't this just bedtime snacking? The potential adverse effects of night-eating symptoms on treatment adherence and outcomes in patients with diabetes. Diabetes Care. 2006;29:1800-4.

16. Jakubowicz D, Wainstein J, Ahren B, Landau Z, BarDayan Y, Froy O. Fasting until noon triggers increased postprandial hyperglycemia and impaired insulin response after lunch and dinner in individuals with type 2 diabetes: a randomized clinical trial. Diabetes Care. 2015;38:1820-6.

17. Reutrakul S, Hood MM, Crowley SJ, Morgan MK, Teodori M, Knutson KL. The relationship between breakfast skipping, chronotype, and glycemic control in type 2 diabetes. Chronobiol Int. 2014;31:64-71.
18. Sato M, Nakamura K, Ogata $H$, et al. Acute effect of late evening meal on diurnal variation of blood glucose and energy metabolism. Obes Res Clin Pract. 2011;5:e220-8.

19. Yabe D, Seino Y, Fukushima M, Seino S. Beta cell dysfunction versus insulin resistance in the pathogenesis of type 2 diabetes in East Asians. Curr Diabetes Rep. 2015;15(6):36.

20. Eto T, Inoue S, Kadowaki T. Effects of once-daily teneligliptin on 24-h blood glucose control and safety in Japanese patients with type 2 diabetes mellitus: a 4-week, randomized, double-blind, placebo-controlled trial. Diabetes Obes Metab. 2012;14:1040-6.

21. Kadowaki T, Kondo K. Efficacy, safety and dose-response relationship of teneligliptin, a dipeptidyl peptidase- 4 inhibitor, in Japanese patients with type 2 diabetes mellitus. Diabetes Obes Metab. 2013;15:810-8.

22. Kadowaki T, Kondo K. Efficacy and safety of teneligliptin in combination with pioglitazone in Japanese patients with type 2 diabetes mellitus. J Diabetes Investig. 2013;4:576-84.

23. Kadowaki T, Kondo K. Efficacy and safety of teneligliptin added to glimepiride in Japanese patients with type 2 diabetes mellitus: a randomized, double-blind, placebo-controlled study with an openlabel, long-term extension. Diabetes Obes Metab. 2014;16:418-25.

24. Kadowaki T, Marubayashi F, Yokota S, Katoh M, Iijima H. Safety and efficacy of teneligliptin in Japanese patients with type 2 diabetes mellitus: a pooled analysis of two Phase III clinical studies. Expert Opin Pharmacother. 2015;16:971-81.

25. Kadowaki T, Inagaki N, Kondo K, et al. Efficacy and safety of canagliflozin as add-on therapy to teneligliptin in Japanese patients with type 2 diabetes mellitus: Results of a 24-week, randomized, doubleblind, placebo-controlled trial. Diabetes Obes Metab. 2017;19:874-82.

26. Kadowaki T, Kondo K, Sasaki N, et al. Efficacy and safety of teneligliptin add-on to insulin monotherapy in Japanese patients with type 2 diabetes mellitus: a 16-week, randomized, double-blind, placebo-controlled trial with an open-label period. Expert Opin Pharmacother. 2017;18:1291-300.

27. Kadowaki T, Haneda M, Ito $H$, et al. Safety and efficacy of long-term treatment with teneligliptin: Interim analysis of a post-marketing surveillance of more than 10,000 Japanese patients with type 2 diabetes mellitus. Expert Opin Pharmacother. 2018;19:83-91. 
28. Daiichi Sankyo Company Limited. Teneligliptin prescribing information. http://www.rad-ar.or.jp/ siori/english/kekka.cgi?n=32722. Accessed 12 Jan 2018.

29. Look AHEAD Research Group. Wing RR. Long-term effects of a lifestyle intervention on weight and cardiovascular risk factors in individuals with type 2 diabetes mellitus: four-year results of the Look AHEAD trial. Arch Intern Med. 2010;170:1566-75.

30. Look AHEAD Research Group, Wing RR, Bolin P, et al. Cardiovascular effects of intensive lifestyle intervention in type 2 diabetes. $\mathrm{N}$ Engl J Med. 2013;369:145-54.

31. Espeland MA, Glick HA, Bertoni A, et al. Impact of an intensive lifestyle intervention on use and cost of medical services among overweight and obese adults with type 2 diabetes: the action for health in diabetes. Diabetes Care. 2014;37:2548-56.

32. Mekary RA, Giovannucci E, Willett WC, van Dam RM, Hu FB. Eating patterns and type 2 diabetes risk in men: breakfast omission, eating frequency, and snacking. Am J Clin Nutr. 2012;95:1182-9.

33. Mekary RA, Giovannucci E, Cahill L, Willett WC, van Dam RM, Hu FB. Eating patterns and type 2 diabetes risk in older women: breakfast consumption and eating frequency. Am J Clin Nutr. 2013;98:436-43.

34. Nakajima K, Suwa K. Association of hyperglycemia in a general Japanese population with late-nightdinner eating alone, but not breakfast skipping alone. J Diabetes Metab Disord. 2015;14:16.

35. Bays HE, Toth PP, Kris-Etherton PM, et al. Obesity, adiposity, and dyslipidemia: a consensus statement from the National Lipid Association. J Clin Lipidol. 2013;7:304-83.
36. Vernon G, Baranova A, Younossi ZM. Systematic review: the epidemiology and natural history of non-alcoholic fatty liver disease and non-alcoholic steatohepatitis in adults. Aliment Pharmacol Ther. 2011;34:274-85.

37. American Diabetes Association. Standards of medical care in diabetes-2018. 3. Comprehensive medical evaluation and assessment of comorbidities. Diabetes Care. 2018;41(Suppl 1):S28-37.

38. Eckel RH, Jakicic JM, Ard JD, et al. 2013 AHA/ACC guideline on lifestyle management to reduce cardiovascular risk: a report of the American College of Cardiology/American Heart Association Task Force on Practice Guidelines. Circulation. 2014;129(25 Suppl 2):S76-99.

39. Teramoto T, Sasaki J, Ishibashi S, et al. Treatment A) lifestyle modification: executive summary of the Japan Atherosclerosis Society (JAS) guidelines for the diagnosis and prevention of atherosclerotic cardiovascular diseases in Japan-2012 version. J Atheroscler Thromb. 2013;20:835-49.

40. Froy O. Metabolism and circadian rhythms-implications for obesity. Endocr Rev. 2010;31:1-24.

41. Panda S. Circadian physiology of metabolism. Science. 2016;354:1008-15.

42. Marcheva B, Ramsey KM, Buhr ED, et al. Disruption of the clock components CLOCK and BMAL1 leads to hypoinsulinaemia and diabetes. Nature. 2010;466:627-31.

43. Liu J, Zhou B, Yan M, et al. CLOCK and BMAL1 regulate muscle insulin sensitivity via SIRT1 in male mice. Endocrinology. 2016;157:2259-69. 